\title{
The influence of the parameters of the diaphragm wall on the deformation of the excavation
}

\author{
Peng-fei CHEN ${ }^{1 a^{*}}$, Xiao-nan GONG $^{1}$ \\ ${ }^{1}$ Research Center of Coastal and Urban Geotechnical Engineering, Zhejiang University, Hangzhou, China
}

\begin{abstract}
A model of a certain excavation was established using PLAXIS 3D, and the measured value was compared with the calculated value. The thickness, elastic modulus, and embedded depth of the diaphragm wall are analysed by the controlled variable method. The graphs of the influence of the above three factors on the deformation of the retaining wall of the excavation, the settlement of the soil outside the pit, and the bending moment of the retaining wall are obtained. The data is relativized to make the comparison result more intuitive and vivid. With the increase of wall thickness or elastic modulus or embedded depth, the deformation of the retaining wall and the settlement of the soil outside the pit will decrease. As the wall thickness or elastic modulus increases, the bending moment of the retaining wall will increase. The embedded depth has almost no effect on the bending moment. The magnitude of the influence on the deformation and force of the excavation is sorted from the largest to the smallest as the wall thickness, the elastic modulus, and the embedded depth.
\end{abstract}

\section{Introduction}

In the design scheme of the enclosure structure for deep excavation, diaphragm wall plus concrete strut is a very common choice ${ }^{1}$. In the entire enclosure system, the proportion of force that the diaphragm wall can share is a very important factor for the design scheme ${ }^{2}$. The three main parameters of the retaining wall, thickness, embedded depth, and elastic modulus have a great influence on the deformation and stress of the excavation. There are many researches on the construction of diaphragm wall. There are also many researches on surrounding buildings, pipelines, foundations, subways, etc. for excavation with diaphragm wall as the main retaining structure ${ }^{3}$. However, there is not much research on the basic problem of sensitivity analysis of the influence of the main parameters of the diaphragm wall itself on the deformation of the excavation ${ }^{4}$.

$\mathrm{Xu}$ Zhonghua ${ }^{5}$ and others studied the deformation of complex deep excavation combining the main underground structure and supporting structure. Chen Pengfei ${ }^{6}$ studied the influence of the retaining function of the water-stop curtain on the deformation of the deep excavation. Liu $\mathrm{Yi}^{7}$ studied the influence of deep mixing pile reinforcement in the passive zone on the deformation of super large and deep excavation. Ma Yun ${ }^{8}$ analyzed the influence of reinforcement parameters in the passive zone of the excavation on the displacement of the supporting structure. Xu Zhonghua ${ }^{2}$ did research on the selection of soil constitutive model in numerical analysis of excavation under sensitive environment.

\section{Engineering background and model establishment}

In the PLAXIS 3D model, the soil is $300 \mathrm{~m}$ long, $300 \mathrm{~m}$ wide, and $75 \mathrm{~m}$ deep. The hardening model is selected for the soil, and the average value of each parameter is taken. The weight $\gamma=19 \mathrm{kN} / \mathrm{m}^{3}$, the cohesion $c=20 \mathrm{kPa}$, the internal friction angle $\varphi=20^{\circ}$, and the three deformation moduli $E_{50}^{r e f}=10 M P a, E_{\text {oed }}^{r e f}=10 M P a$, $E_{\mathrm{ur}}^{r e f}=60 M P a$, Poisson's ratio $v=0.25$. The excavation is $100 \mathrm{~m}$ long, $50 \mathrm{~m}$ wide and $15 \mathrm{~m}$ deep. The enclosure structure is an underground continuous wall (plate), the wall depth is $30 \mathrm{~m}$, the embedded depth is $15 \mathrm{~m}$, and the wall thickness is $0.8 \mathrm{~m}$. There are 3 layers of inner support, respectively at depths of $0 \mathrm{~m},-5 \mathrm{~m}$, and $-10 \mathrm{~m}$. The retaining wall and internal support are both concrete structures ${ }^{9}$, with elastic modulus $E=30 G P a$ and Poisson's ratio $v=0.15$.

Set this model as the reference model. The influence of various variables on the deformation of the excavation will be discussed below. All changes in a single variable are made on this reference model, and other parameters remain unchanged.

Based on the above data, the model was established. The deformation calculation results and measured data of

${ }^{1}$ Corresponding author: 21212003@zju.edu.cn 
the envelope structure are shown in the figure 1.

It can be seen from the figure 1 that the model calculation result is relatively close to the actual measurement result, and the maximum lateral displacement of the wall calculated by the model is slightly larger than the actual measurement value.

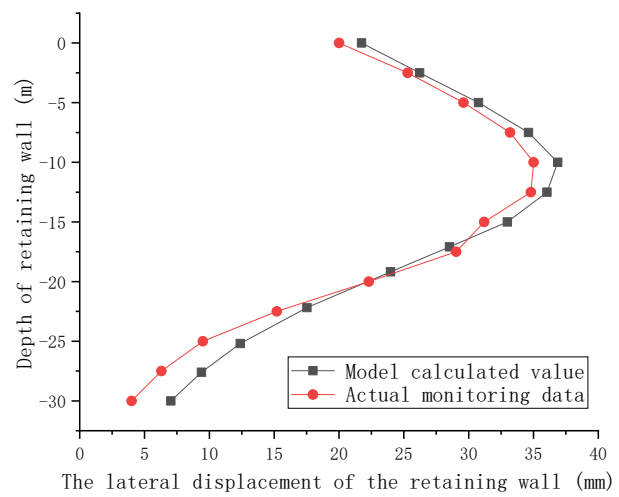

Fig. 1. Comparison of measured value and calculated value.

\section{Results and Discussion}

\subsection{The influence of elastic modulus}

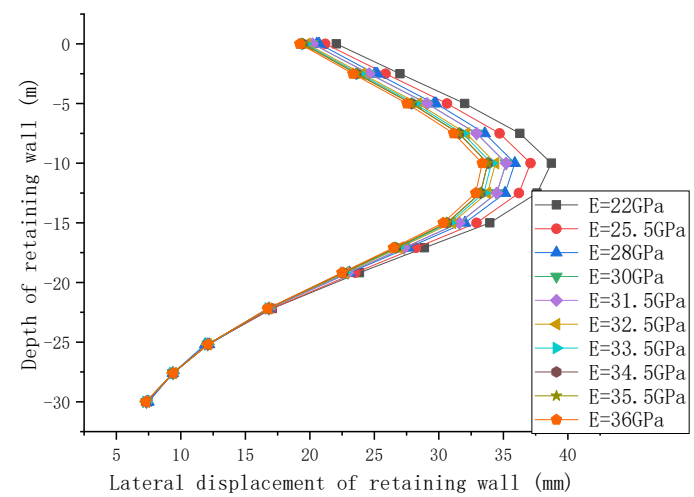

Fig. 2. The influence of elastic modulus on deformation.

The figure 2 is the relationship between the lateral displacement of the retaining wall and the elastic modulus $\mathrm{E}$ of the diaphragm wall. When increasing from $\mathrm{E}=22 \mathrm{GPa}$ to $\mathrm{E}=36 \mathrm{GPa}$, the displacement of the retaining wall decreases from $38.7 \mathrm{~mm}$ to $33.36 \mathrm{~mm}$, which is about $14 \%$ reduction. As E increases, the displacement is decreasing, and the degree of decrease is slowing down. Because the increase of the concrete strength grade makes the reduction of the displacement not significant, but the increase in the cost is a lot, so most of the selection of the retaining wall concrete is mainly $\mathrm{C} 30$.

The figure 3 is the relationship between the bending moment of the retaining wall and the elastic modulus $\mathrm{E}$ of the diaphragm wall. When increasing from $\mathrm{E}=22 \mathrm{GPa}$ to $\mathrm{E}=36 \mathrm{GPa}$, the bending moment of the diaphragm wall increases from $627.9 \mathrm{kN} . \mathrm{m} / \mathrm{m}$ to $783.6 \mathrm{kN} . \mathrm{m} / \mathrm{m}$, an increase of about $25 \%$. As $\mathrm{E}$ increases, the bending moment increases, and the degree of increase slows down. Combining the above two figures, it can be seen that as the elastic modulus $\mathrm{E}$ of the retaining wall increases, the force on the retaining wall increases, but its deformation decreases. The reason is analyzed as follows. The increase in E increases the flexural rigidity of the retaining wall, so that the proportion of the force shared by the retaining wall in the retaining system (including the retaining wall and strut) increases, so the bending moment value is increasing However, the deformation of the retaining wall is determined by the ratio of force to rigidity. The increase in force is not as great as the increase in rigidity, so its deformation is decreasing.

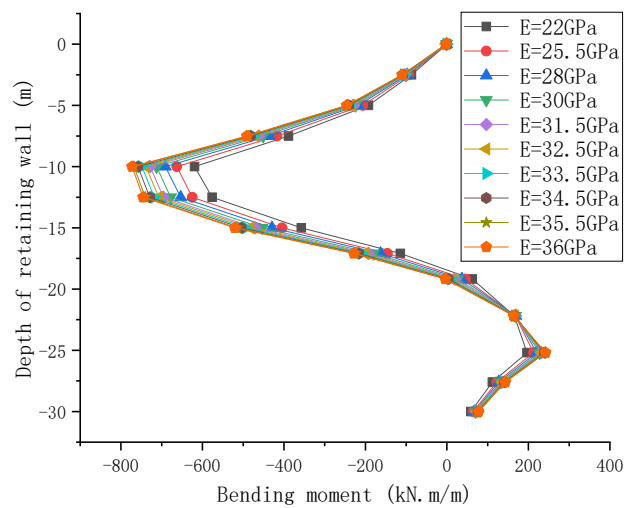

Fig. 3. The influence of elastic modulus on bending moment

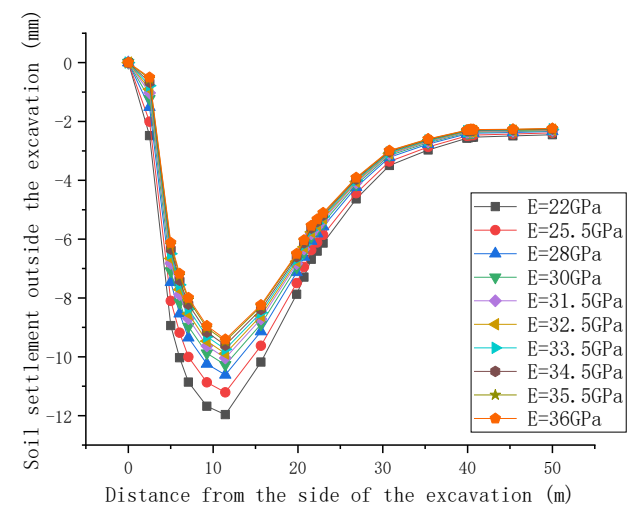

Fig. 4. The influence of elastic modulus on settlement.

The figure 4 shows the relationship between the soil settlement on the outer surface of the pit and the elastic modulus $\mathrm{E}$ of diaphragm wall. It can be seen from the figure that when $\mathrm{E}=22 \mathrm{GPa}$ is increased to $\mathrm{E}=36 \mathrm{GPa}$, the settlement decreases from $11.89 \mathrm{~mm}$ to $9.403 \mathrm{~mm}$, a decrease of about $20 \%$. As E increases, the settlement decreases, and the degree of decrease is slowing down.

\subsection{The influence of thickness}

The figure 5 shows the relationship between the thickness $\mathrm{d}$ of the retaining wall and the lateral displacement of the diaphragm wall. In the benchmark model in this paper the thickness $\mathrm{d}=0.8 \mathrm{~m}$. when $\mathrm{d}=0.8 \mathrm{~m}$ is reduced to $\mathrm{d}=0.4 \mathrm{~m}$, the lateral displacement of the wall increases from $35.2 \mathrm{~mm}$ to 
$65.3 \mathrm{~mm}$, an increase of about $85 \%$, which is a too large increase. When increasing from $\mathrm{d}=0.8 \mathrm{~m}$ to $\mathrm{d}=1.4 \mathrm{~m}$, the lateral displacement decreases from $35.2 \mathrm{~mm}$ to $21.7 \mathrm{~mm}$, a decrease of about $40 \%$. As the thickness increases, the lateral displacement of the retaining wall gradually decreases, and the degree of decrease is slowing down.

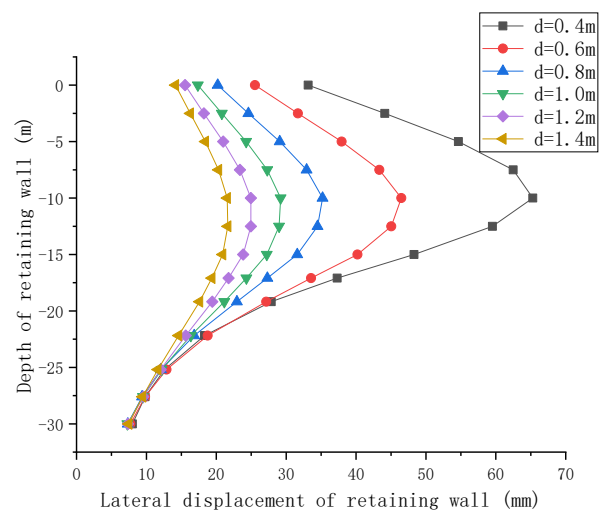

Fig. 5. The influence of thickness on deformation.

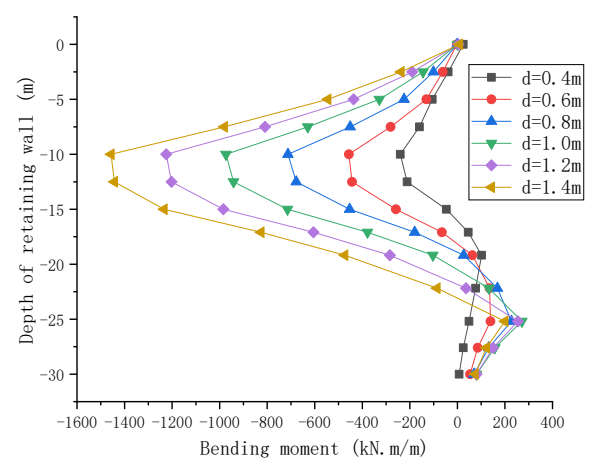

Fig. 6. The influence of thickness on bending moment.

The figure 6 is the relationship between the bending moment of the retaining wall and the thickness $d$ of the diaphragm wall. When increasing from $\mathrm{d}=0.4 \mathrm{~m}$ to $\mathrm{d}=1.4 \mathrm{~m}$, the bending moment of the retaining wall increases from $252 \mathrm{kN} . \mathrm{m} / \mathrm{m}$ to $1457 \mathrm{kN} . \mathrm{m} / \mathrm{m}$, an increase of about 4.8 times, and the increasing speed is almost uniform. Combining the above two figures, it can be seen that as the thickness $d$ increases, the force on the retaining wall increases, while its deformation decreases. The reason is analyzed as follows. The increase in thickness increases the flexural rigidity of the retaining wall, so that the proportion of the force shared by the retaining wall in the retaining system (including the retaining wall and the internal support) increases, so the bending moment value is increasing. However, the deformation of the retaining wall is determined by the ratio of force to rigidity. The increase in force is not as great as the increase in rigidity, so its deformation is decreasing.

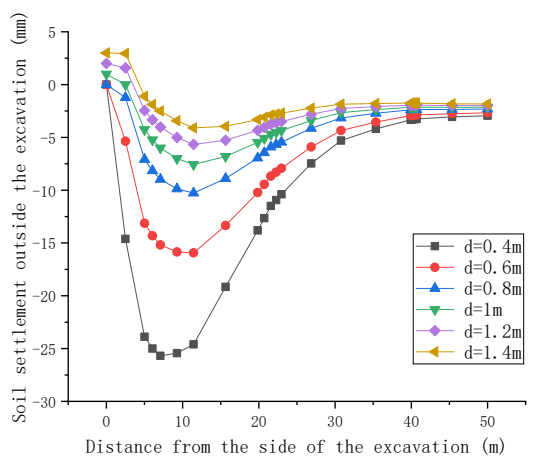

Fig. 7. The influence of thickness on settlement

The figure 7 shows the relationship between the thickness $d$ of the retaining wall and the settlement of the soil outside the pit. In the benchmark model in this paper $\mathrm{d}=0.8 \mathrm{~m}$. when $\mathrm{d}=0.8 \mathrm{~m}$ is reduced to $\mathrm{d}=0.4 \mathrm{~m}$, the settlement increases from $10.25 \mathrm{~mm}$ to $25.8 \mathrm{~mm}$, which is an increase of 1.5 times, which is a large increase. When increasing from $\mathrm{d}=0.8 \mathrm{~m}$ to $\mathrm{d}=1.4 \mathrm{~m}$, the settlement decreases from $10.25 \mathrm{~mm}$ to $6.7 \mathrm{~mm}$, a decrease of about $35 \%$. As the thickness increases, the settlement gradually decreases, and the degree of decrease is slowing down.

\subsection{The influence of embedded depth of diaphragm wall}

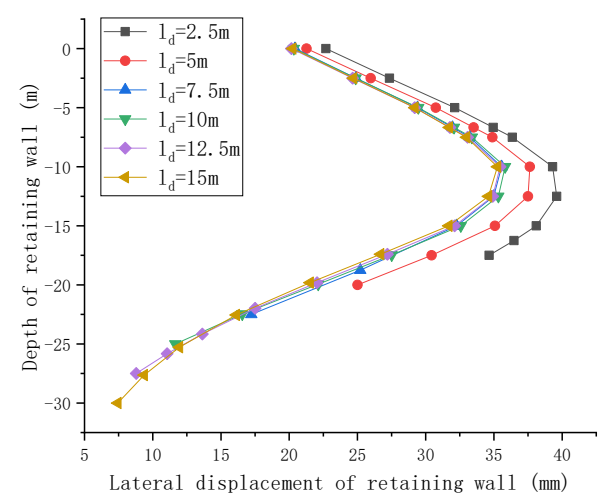

Fig. 8. The influence of embedded depth on deformation. The figure 8 is the relationship between the lateral displacement of the retaining wall and the embedded depth of diaphragm wall. When increasing from $l_{d}=$ $2.5 \mathrm{~m}$ to $l_{d}=7.5 \mathrm{~m}$, the lateral displacement is reduced from $39.62 \mathrm{~mm}$ to $35.57 \mathrm{~mm}$, a decrease of about $10 \%$. When $l_{d}>7.5 m$, the lateral displacement is basically unchanged. Therefore, the reasonable embedded depth of the diaphragm wall is $7.5 \mathrm{~m}$. 


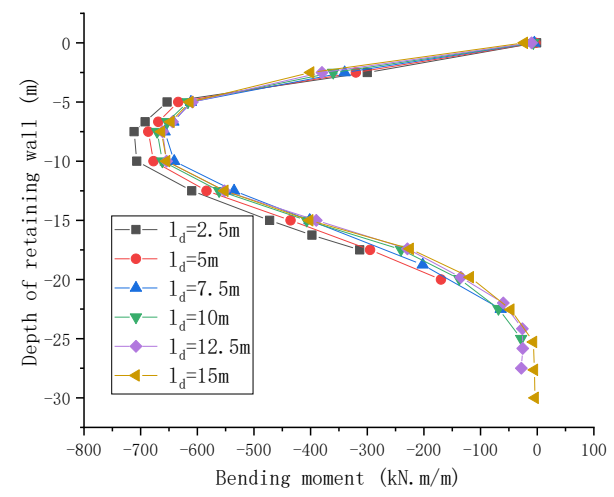

Fig. 9. The influence of embedded depth on bending moment.

The figure 9 is the relationship between the bending moment of the retaining wall and the embedded depth $l_{d}$ of the diaphragm wall. When increasing from $l_{d}=2.5 \mathrm{~m}$ to $l_{d}=7.5 \mathrm{~m}$, the bending moment of the diaphragm wall decreases, from $711 \mathrm{kN} . \mathrm{m} / \mathrm{m}$ to $663 \mathrm{kN} . \mathrm{m} / \mathrm{m}$, a decrease of about $7 \%$, and the decrease is not large. When $l_{d}>7.5 \mathrm{~m}$, the bending moment of the retaining wall basically no longer decreases.

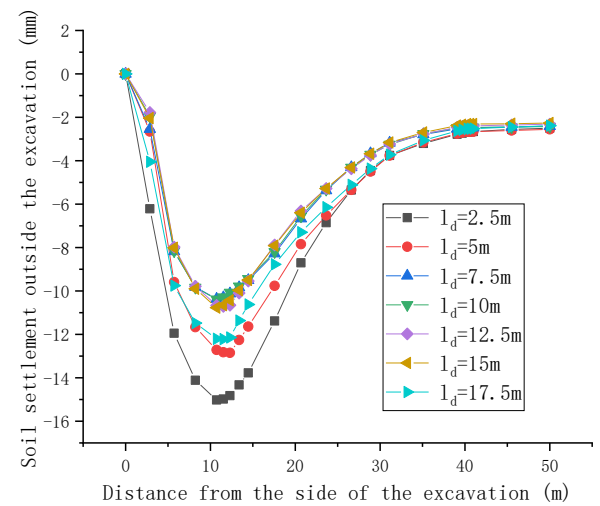

Fig. 10. The influence of embedded depth on settlement

The figure 10 shows the relationship between the settlement of the soil outside the pit and the embedded depth of the diaphragm wall. When increasing from $l_{d}=$ $2.5 \mathrm{~m}$ to $l_{d}=7.5 \mathrm{~m}$, the settlement decreases from $15.19 \mathrm{~mm}$ to $10.27 \mathrm{~mm}$, a decrease of about $33 \%$. When $l_{d}>7.5 \mathrm{~m}$, the settlement is basically unchanged. Therefore, the reasonable embedded depth of the wall is $7.5 \mathrm{~m}$.

\section{Relativization of data}

In order to know more clearly the influence of various factors on the calculation results, we further process the data to make the law more vivid.

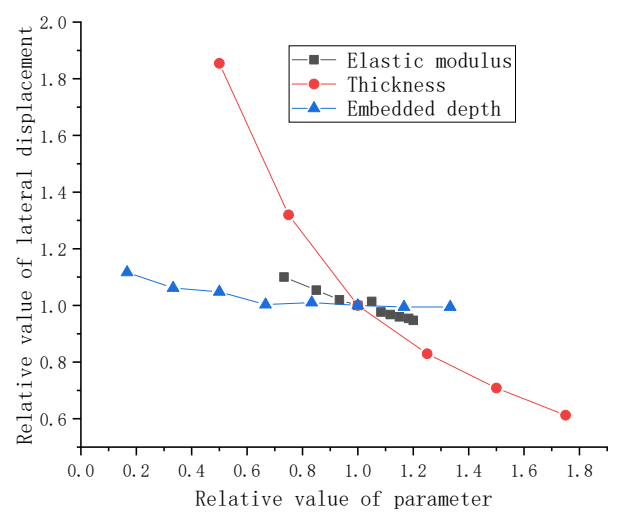

Fig. 11. Sensitivity to lateral displacement

Briefly explain the meaning of each data in the figure. The meaning represented by the horizontal axis is the ratio of each parameter to the corresponding parameter in the reference model. The meaning represented by the vertical axis is the ratio of the calculation result to the calculation result in the reference model. All images pass through the point $(1,1)$, which means that each curve is just in the state of the reference model. Take the first point $(0.5,1.9)$ on the leftmost side of the curve of thickness $d$ as an example. The abscissa is 0.5 , indicating that the thickness of the slab wall is 0.5 times the thickness in the reference model at this time. The ordinate is 1.9 , indicating the lateral displacement calculated at this time is 1.9 times the lateral displacement in the reference model.

The above figure is the sensitivity image of the lateral displacement to the three parameters of the retaining wall. It can be seen that the three curves are all inclined downward curves, but the degree of inclination of each curve is very different. They are explained separately below.

The curve of the thickness of the retaining wall is the steepest among the three curves, indicating that the lateral displacement of the retaining wall is the most sensitive to the thickness of the retaining wall. That is, the thickness has the largest and most obvious influence on the lateral displacement. We can find that although the curve as a whole is very steep, it also has a gradual slowing down trend. It can be inferred that an asymptote will appear later (note that the ordinate of this image does not start from zero). It shows that as the thickness 1 increases, the lateral displacement will decrease, but the rate of decrease will slow down.

The curve of the elastic modulus $\mathrm{E}$ is a straight line obliquely downward, indicating that as $\mathrm{E}$ increases, the lateral displacement decreases linearly. However, this is not to say that this trend can continue. We can see that this curve is very short compared to the other two, which means that the variable range of the $\mathrm{E}$ is actually very small. According to the concrete design specification, the elastic modulus of concrete increases with the increase of concrete strength grade, but its speed is getting slower and slower. It can also be seen from the figure that as the abscissa increases, the points on the curve become denser, which means that the increase in the strength of concrete slows down the increase in its elastic modulus. 
The curve of the embedded depth $l_{d}$ is relatively gentle as a whole, which looks like a straight line. This is because the other curve is relatively steep, so that the slope of this curve is not easy to detect. In fact, it can be discussed in two sections at $\lambda=0.67$ (that is, the embedded depth is $10 \mathrm{~m}$ ). When $\lambda<0.67$, the slope is relatively large, which is basically the same as the slope of the elastic modulus curve. When $\lambda>0.67$, it is a horizontal straight line, indicating that the increase in the embedded depth at this time cannot limit the lateral movement of the retaining wall. Therefore, from the perspective of limiting deformation, the best embedded depth is $10 \mathrm{~m}$.

Sorting the sensitivity of the above three factors, the following inequality can be roughly obtained:

$$
d \gg E \approx l_{d}(\lambda<0.67)>l_{d}(\lambda>0.67) \approx 0
$$

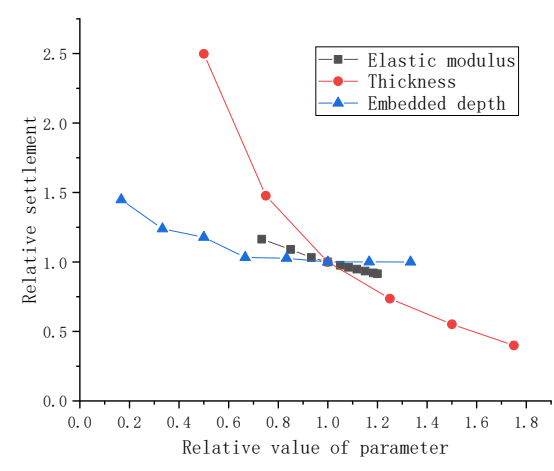

Fig. 12. Sensitivity to settlement

The figure 12 is the sensitivity image of settlement to the three parameters of the retaining wall. It can be seen that the three curves are all inclined downward curves, but the degree of inclination of each curve is very different. They are explained separately below.

The curve of $d$ is the steepest among the three curves, indicating that the settlement is the most sensitive to the thickness of the retaining wall. That is, the thickness has the largest and most obvious influence on the settlement. We can find that although the curve as a whole is very steep, it also has a gradual slowing down trend. It can be inferred that an asymptote will appear later. It shows that as $d$ increases, the settlement will decrease, but the rate of decrease will slow down.

The curve of the modulus of elasticity $\mathrm{E}$ is a straight line obliquely downward, indicating that the settlement decreases linearly with E. However, this is not to say that this trend can continue. The reason is the same as the sensitivity curve of lateral displacement described earlier.

The curve of the embedded depth can be divided into two sections for discussion at $\lambda=0.67$ (that is, the embedded depth is $10 \mathrm{~m}$ ). When $\lambda<0.67$, the slope is relatively large, which is basically the same as the slope of the elastic modulus curve. When $\lambda>0.67$, it is a horizontal straight line, indicating that the increase in the embedded depth at this time cannot make the settlement decrease. Therefore, from the perspective of limiting settlement, the best embedded depth is $10 \mathrm{~m}$.

Sorting the sensitivity of the above three factors, the following inequality can be roughly obtained:

$$
d \gg E \approx l_{d}(\lambda<0.67)>l_{d}(\lambda>0.67) \approx 0
$$

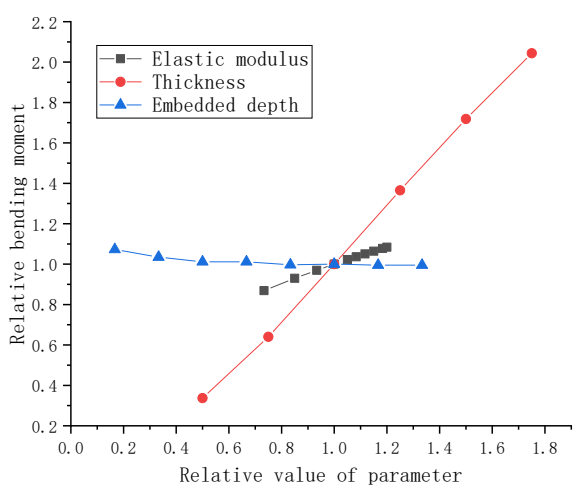

Fig. 13. Sensitivity to bending moment

The figure 13 is the sensitivity image of the bending moment of the retaining wall and the three parameters. We can see that the three curves are all straight lines, but two of them are upward straight lines and one is downward straight lines. The following are respectively analyzed. The curve of the thickness of the retaining wall is the steepest among the three curves, indicating that the bending moment is the most sensitive to thickness. That is, the thickness has the largest and most obvious influence on the bending moment. The curve is a straight line obliquely upward, indicating that the bending moment increases linearly with the increase of thickness, which is completely different from the sensitive curve of the influence of thickness on the lateral displacement and settlement. It needs to be explained here that as thickness increases, the force shared by the wall will increase, and the bending moment will increase linearly, but its deformation will decrease instead. This is because the deformation is determined by the force and the bending resistance. The stiffness ratio is determined, and the flexural stiffness is proportional to the cube of thickness, so the increase in force is not as large as the increase in stiffness. As a result, the force increases and the deformation decreases.

The curve of the elastic modulus $\mathrm{E}$ is an obliquely upward straight line, indicating that as $\mathrm{E}$ increases, the bending moment increases linearly. However, the slope of this straight line is much smaller than that of the thickness of the retaining wall, indicating that $\mathrm{E}$ has far less influence on the bending moment than $\mathrm{d}$. Moreover, this increasing trend cannot continue, because the change range of elastic modulus is relatively small. For details, please refer to the aforementioned analysis of sensitivity to lateral displacement.

The curve of the embedded depth 1_d is a straight line inclined slightly downward. It shows that with the increase of the embedded depth of the retaining wall, the bending moment is slowly decreasing, which is completely different from the law of the other two curves, and the other two are upward straight lines.

Sorting the sensitivity of the above three factors, the following inequality can be roughly obtained:

$$
d \gg E>l_{d} \approx 0
$$




\section{Conclusion}

With the increase of wall thickness $\mathrm{d}$ or elastic modulus $\mathrm{E}$ or embedded depth $l_{d}$, the deformation of the retaining wall and the settlement of the soil outside the pit will decrease. As the wall thickness d or elastic modulus $\mathrm{E}$ increases, the bending moment of the retaining wall will increase. The embedded depth has almost no effect on the bending moment.

The magnitude of the influence on the deformation and force of the excavation is sorted from the largest to the smallest as the wall thickness $\mathrm{d}$, the elastic modulus $\mathrm{E}$, and the embedded depth $l_{d}$.

\section{References}

1. Liu, G.B., Wang, W.D. (2009) Excavation engineering handbook. China Architecture and Building Press, Beijing

2. Xu, Z.H., Wang, W.D. (2010) Selection of soil constitutive models for numerical analysis of deep excavations in close proximity to sensitive properties. Rock and Soil Mechanics, 31(1): 258264.

3. Liu, C. (2008) Analysis of deformation and stress due to deep excavation considering different deformation and strength parameters of soil and space effect of excavation and retaining structure. Tianjin University, Tianjin.

4. Wang, W.D., Wang H.R., Xu, Z.H. (2012) Experimental study of parameters of hardening soil model for numerical analysis of excavations of excavations. Rock and Soil Mechanics, 33(8): 2283-2290.

5. Xu, Z.H., Wang, J.H., Wang, W.D. (2006) Analysis of a complicated deep excavations supported by substructures. Chinese Journal of Geotechnical Engineering, 28(S1): 1355-1359.

6. Chen, P.F., Gong, X.N., Liu, N.W. (2014) Effect of curtain's role in retaining on deformation of deep excavations. Chinese Journal of Geotechnical Engineering, 36(11): 254-258.

7. Liu, Y., Li, J.P. (2012) Effect of reinforcement of deep mixing piles on deformation of ultra-deep excavation in passive zone. Chinese Journal of Geotechnical Engineering, 34(11): 465-469.

8. MA, Y., Qu, R.F., Zhou, X.T. (2012) Effects of reinforcement parameters in passive zone of excavations on lateral deformation of supporting structures. Chinese Journal of Geotechnical Engineering, 34(S1): 190-196.

9. Zhao, J.D., Xu, Y.L., Huang, X.K. (2015) Code for design of concrete structures. Ministry of housing and urban rural development of the people's Republic of China, Beijing 